\title{
Perception of Jordanian Pharmacy Students towards Community Pharmacy-Virtual Training Experience during COVID-19 Outbreak
}

Muna Barakat ( $\nabla$ m_barakat@asu.edu.jo )

Applied Science Private University

Rajaa A. Al-Qudah

Applied Science Private University

Rana Abu Farha

Applied Science Private University

Husam A. ALSalamat

Al-Balqa`Applied University

Amal Akour

University of Jordan

Research Article

Keywords: COVID-19, Jordan, Pharmacy Training, Pharmacy students, Virtual

Posted Date: February 22nd, 2021

DOI: https://doi.org/10.21203/rs.3.rs-268142/v1

License: (c) (1) This work is licensed under a Creative Commons Attribution 4.0 International License. Read Full License 


\section{Abstract}

Background: Nowadays, it is clear for the whole world that the coronavirus disease (COVID-19) pandemic had substantial consequences on various sectors including social, economic and education. Pharmacy education includes community pharmacy practice training, and in many schools, it has been shifted to virtual modality utilizing distance learning. This study aims to assess the perception of pharmacy students towards community pharmacy practice virtual training during the COVID-19 period.

Methods: Senior pharmacy students were included in this study. Accredited and certified community pharmacy preceptors were asked to simulate the community pharmacy training and record that as videos, which were evaluated and assessed by expert academics before being delivered to students. A validated online questionnaire was then distributed for the students for self-administration through Microsoft teams to evaluate their perception.

Results: A convenience sample $(n=109)$ of senior pharmacy students were recruited. The majority of the participants were females $(70.6 \%)$ and the median age of students was 22.0 years (IQR=1). Around half of the participants showed positive perceptions towards the virtual training module and the pharmacy training preceptors. A $46.8 \%$ of the students benefited from the virtual training in time management and $43.1 \%$ in developing lifelong learning skills. The absence of eye contact during the learning was the most important barrier revealed by the students (52.3\%). Half of the students agreed/strongly agreed that combining the virtual and conventional techniques for future training would improve training outcomes

Conclusion: This is the first study assessing perception towards virtual training in Jordan, which was positive among pharmacy students. Such results could spot the light on the value of hybrid education and training (virtual with actual) in the pharmacy field. However, there is a crucial need for well-designed studied modules to comply with the intended learning outcomes.

\section{Introduction}

A dramatic change in the development and the use of online courses have been noticed in the last years $(1,2)$. Moving from face-to-face, teacher-student interaction to online learning has grown intensely with emphasizing on and understanding how to have the best engagement with the students, with the ultimate goal to achieve optimum learning outcomes (3). However, the environment of the online courses is critical to its success (4). For example in online teaching, students appear to need more direct feedback from their professors than in a conventional method of teaching (4). A study by Bangert found that students seek prompt comments and feedback specifically related to problems they have when using online course platform management tools and while submitting quizzes and assignments (5).

Several factors have resulted in this shift to online courses including program marketability, student adaptability and suitability, and the rapid growth of technology and internet access (6). Furthermore, during the year 2020, the world has faced a coronavirus disease (COVID-19) outbreak which has significantly impacted the education and teaching strategies worldwide $(3,7)$. Due to the outbreak, all 
classes were switched to online learning (7) which was found to be the most effective tool to maintain students' access to learning and keep their retention.

Thus, university/faculty higher education must evaluate the student's satisfaction with online courses especially those who have clinical training such as healthcare students $(2,8,9)$. As reported by Rothman et al (2), students showed overall satisfaction with online courses, with somewhat lower satisfaction regarding aspects pertaining to instructor feedback and technology. On the other hand, healthcare students have struggled differently where their clinical training has been moved completely to a virtual modality in order to reduce the risk of infection (10). To date, no studies have assessed the virtual training for healthcare students including pharmacists, nurses, etc. The published literature focused on the actual training assessment (10). For instance, a study by Abu Farha et. al. in Jordan aimed to evaluate the perceptions of undergraduate pharmacy students regarding their current pharmacy training practices and experiences before the COVID-19 outbreak (10). They found that more than half of students had positive attitudes toward training sites and had positive feedback about the outcomes of their training experience. However, only $50 \%$ of students had positive feedback concerning the effect of training on the increase in their satisfaction with the pharmacy profession (10).

Although there is an increase in the use of online courses, educational institutions have not adequately addressed healthcare student evaluations of such online courses including virtual training which remains a critical component in education. This study is the first study of its type which aimed to evaluate the perception of final years' pharmacy students with virtual community-based education (the community pharmacy field training) as a result of the COVID-19 outbreak and the influence of different variables on their perception via a validated questionnaire.

\section{Method}

\section{Study design and participants}

This study is a descriptive cross-sectional that was conducted in Jordan in the first two weeks of December 2020 using an online survey that was administered to a convenience sample of pharmacy students. The online survey was developed and validated by clinical researchers to solicit anonymous responses, which were treated confidentially. The inclusion criteria were senior (fifth-year) pharmacy students who are registered in the "Training II" course at the faculty of pharmacy/Applied Science Private University located in Amman-Jordan and were able to comprehend English.

The structure of the "Training II" course was as following: there were five selected community pharmacists who were accredited and certified by the Faculty of Pharmacy at Applied Science Private University as community pharmacy training preceptors. They had recorded different videos related to different topics determined by the course instructor including the cardiovascular system, respiratory system endocrine system, infectious diseases, and gastrointestinal system. The preceptors had covered in the videos the most important information related to the drugs; for instance, different trade names, 
drug indications, mechanism of actions, side effects, and the most relevant patient's counseling points. The videos were recorded in the community pharmacy setting to simulate the real practice and the layout of the pharmacy. Expert academics in the field of pharmacy practice have evaluated the videos before submission to the students. The students were asked to watch the videos which were uploaded by the course instructor via the educational platform (Microsoft Teams ${ }^{\circledR}$ ). Discussion with students which was led by the course instructor was completed to achieve the course learning outcomes.

Participants were recruited through the educational platform (Microsoft Teams $®$ ). Participants were advised that their participation in the study was voluntary and did not pose any risks. A written participant consent statement "Dear Students, researchers are carrying out this research project to assess the perceptions of pharmacy students towards the virtual training experience. This survey was developed for this purpose; it may take you up to 15 minutes to be filled. We would like to confirm that all information provided here will be kept confidential, and will be used only for research purposes. Your participation in completing this survey is highly appreciated. Kindly mark the statement that applies to you" was given to the participants at the beginning of the survey.

If the participants were willing to proceed with the survey, they approved their consent. If not, they selected "disagree to participate" and did not continue with the survey questions.

Potential participants who completed the survey were considered to have given informed consent for their participation in the study.

The Ethical approval for the study was obtained from the Faculty of Pharmacy, Applied Science Private University (Approval number: 2020-PHA-31).

\section{Survey development, validation, and reliability}

The online survey was developed after reviewing related validated surveys in the literature $(2,8,11,12)$, and was designed using the general principles of good survey design (13). Several sources were used to generate a pool of questions considered to be relevant to the aim of the study (13). The online survey was finally prepared in English using Google Forms ${ }^{\circledR}$. The survey contained multiple-choice and open-ended questions and was designed to be completed within 10-15 minutes.

To ensure face validity, the first draft of the survey was evaluated by three independent academic staff members who had previous experience in survey development and pharmacy training-related work and research studies. A statistician was also involved at this stage of the evaluation. All the provided comments and feedback were considered and incorporated where appropriate to prepare the final version of the survey. The questions were free from medical jargon or difficult terminology. Finally, the survey was piloted via a sample of 30 students, which were not included in the final analysis. This stage of the study was conducted to enhance clarity, readability, understandability, and confirm the study's applicability to the students. The reliability of the questionnaire was assessed using Cronbach's a measure, with value $=$ 0.850 indicating acceptable internal consistency. 
The final version of the survey contained four parts. Part one comprised seven questions, which included sociodemographic and general information such as gender, age, nationality, and the number of completed field training hours before the virtual training course. The second part assessed pharmacy students' perception towards training preceptors; here potential participating students were asked to rate their level of agreement with the following statements "Pharmacy preceptors acknowledge the objectives of training"; "Pharmacy preceptors acknowledge your role as a training student"; "Pharmacy preceptors help students integrate their knowledge of drug therapy into patient care", etc.

The third part reflected pharmacy students' perceptions toward the virtual training module. Here, the students were asked about the benefits of the virtual training module from their perception and barriers of the virtual training module from their perception. The last part compared the virtual training vs conventional community pharmacy training. Students were asked if they had the chance to modify the quality of the virtual training, to what level they will agree on the given suggestions such as "converting the video records to interactive meetings with the training preceptors"; "changing the used online platform (i.e. Microsoft teams) to a different one", "keep the training sessions with one preceptor rather than multiple preceptors", "combine the virtual with the conventional for future training" and "no modifications are required". A 5-level Likert scale was used to assess participants' responses to sections two-four i.e., "Strongly agree", "Agree", "Neutral", "Disagree", or "Strongly disagree".

\section{Sample size}

The sample was taken from the total number of registered 5th -year pharmacy students in the training II course $(n=110)$. Based on Tabachnick and Fidell recommendation for sample size calculation in analysis, 5-20 subjects per predictor are suggested to be desirable (14). Based on the number of independent variables levels used in this study $(n=6)$ and using the number of 10 subjects per predictor level, a minimum sample size of 60 or higher was considered suitable for the purpose of this study.

\section{Statistical analyses}

The completed surveys were extracted from Google Forms ${ }^{\circledR}$ as an Excel sheet and were then exported to Statistical Package for Social Sciences version 22.0 (SPSS ${ }^{\circledR}$ Inc., Chicago, IL, USA) for the statistical analysis. The descriptive statistics included frequency and percentages for categorical variables (both nominal and ordinal) and using median/interquartile range (IQR) means for continuous variables. Cronbach's a was used to evaluate the reliability of the questionnaire i.e. that the scales constructed are fit for their purpose, with values $\geq 0.7$ indicates acceptable internal consistency (15).

\section{Results}

\section{Sociodemographic characteristics of the study participants}

During the study period, 109 pharmacy students completed the questionnaire out of 110 students registered in the training $\mathrm{II}$ course (response rate $=99.1 \%$ ). More than two-thirds of the students were females $(n=77,70.6 \%)$. The median age of students was 22.0 years $(I Q R=1)$, and they completed a 
median of 888.0 field training hours $(\mathrm{IQR}=539.5)$ before registering for this course. The majority of students reside in Amman (the capital of Jordan), and only 35.8\% of them $(n=39)$ were Jordanians. More than half of the students $(n=63,57.8 \%)$ reported taking a previous virtual training course before this one. Demographic characteristics are presented in Table 1.

Table 1

Demographic characteristics of the study participants $(n=109)$

\begin{tabular}{|c|c|c|}
\hline Parameter & Median (IQR) & $\mathrm{n}(\%)$ \\
\hline Age (years) & $22.0(1.0)$ & \\
\hline Gender & & $77(70.6)$ \\
\hline Female & & $32(29.4)$ \\
\hline \multicolumn{3}{|l|}{ Male } \\
\hline Residential area & & $85(78.0)$ \\
\hline Amman (the capital of Jordan) & & $24(22.0)$ \\
\hline \multicolumn{3}{|l|}{ Others } \\
\hline Nationality & & $39(35.8)$ \\
\hline Jordanian & & $70(64.2)$ \\
\hline \multicolumn{3}{|l|}{ Other } \\
\hline Completed field training hours & $888.0(539.5)^{\star}$ & \\
\hline Previous pharmacy virtual training course & & $46(42.2)$ \\
\hline No & & $63(57.8)$ \\
\hline \multicolumn{3}{|l|}{ Yes } \\
\hline IQR: interquartile range, *out of $1440 \mathrm{hr}=$ th & required field trai & ing hours. \\
\hline
\end{tabular}

Students reported adequate perceptions towards preceptors participated in their virtual training course (Fig. 1), where $65.1 \%$ of them $(n=71)$ believed that preceptors have acknowledged their role as training students, and $57.8 \%$ of them $(n=63)$ agreed/strongly agreed that preceptors have helped them integrating their knowledge of drug therapy into patient care. Also, $55.0 \%$ of the students believed that preceptors assisted them in achieving the objectives set for their training. Students had fewer positive attitudes of preceptors regarding their application of interesting learning activities ( $n=51,46.8 \%)$.

\section{Pharmacy Students' perception towards the virtual training module}


Students also showed inadequate perception towards the benefit of their virtual training module concerning helping them to manage their time efficiently $(n=51,46.8 \%)$, reducing the stress of real exposure to patients $(n=49,44.9 \%)$, developing lifelong learning skills $(n=47,43.1 \%)$, giving them the chance to think critically $(n=46,42.2 \%)$, and helping them to develop social skills ( $n=43,39.5 \%)$. More details are summarized in Table 2.

Table 2

Pharmacy Students' benefits of the virtual training module $(n=109)$

\begin{tabular}{|llll|}
\hline Statements & $\begin{array}{l}\text { Strongly } \\
\text { agree } \\
\text { /Agree }\end{array}$ & Neutral & $\begin{array}{l}\text { Strongly } \\
\text { disagree/Disagree }\end{array}$ \\
\hline $\begin{array}{l}\text { The virtual training experience increased my } \\
\text { involvement with the pharmacy profession }\end{array}$ & $59(54.1)$ & $\begin{array}{l}32 \\
(29.4)\end{array}$ & $18(16.5)$ \\
\hline $\begin{array}{l}\text { The virtual training module helped me to understand } \\
\text { many training related topics proficiently }\end{array}$ & $59(50.1)$ & $\begin{array}{l}29 \\
(26.6)\end{array}$ & $21(19.3)$ \\
\hline $\begin{array}{l}\text { The virtual training module gives an opportunity to } \\
\text { see/know the medications before real exposure to the } \\
\text { patients }\end{array}$ & $61(56.0)$ & 33 & $15(13.8)$ \\
\hline $\begin{array}{l}\text { The virtual training module helped me to manage my } \\
\text { time efficiently }\end{array}$ & $51(46.8)$ & $\begin{array}{l}37 \\
(33.9)\end{array}$ & $21(19.3)$ \\
\hline $\begin{array}{l}\text { The virtual training module reduces the stress of real } \\
\text { exposure to patients }\end{array}$ & $49(44.9)$ & $\begin{array}{l}39 \\
(35.8)\end{array}$ & $21(19.3)$ \\
\hline $\begin{array}{l}\text { The virtual training experience helped me to develop } \\
\text { social skills }\end{array}$ & $43(39.5)$ & $\begin{array}{l}39 \\
(35.8)\end{array}$ & $27(24.8)$ \\
\hline $\begin{array}{l}\text { The virtual training module gives the chance to think } \\
\text { critically }\end{array}$ & $46(42.2)$ & $\begin{array}{l}44 \\
(40.4)\end{array}$ & $19(17.4)$ \\
\hline $\begin{array}{l}\text { The virtual training experience is a development of } \\
\text { lifelong learning skills/completion of the experiential } \\
\text { learning cycle }\end{array}$ & $47(43.1)$ & $\begin{array}{l}43 \\
(39.4)\end{array}$ & $19(17.4)$ \\
\hline $\begin{array}{l}\text { The virtual training module improved my self-directed } \\
\text { learning skills. }\end{array}$ & $57(52.3)$ & $\begin{array}{l}32 \\
(29.4)\end{array}$ & $20(18.3)$ \\
$\begin{array}{l}\text { The virtual training module pushed me to improve my } \\
\text { IT skills. }\end{array}$ & $61(56.0)$ & $\begin{array}{l}30 \\
(27.5)\end{array}$ & $18(16.5)$ \\
\hline $\begin{array}{l}\text { The virtual training module assignments pushed me to } \\
\text { learn how to search for information efficiently }\end{array}$ & $70(64.2)$ & $\begin{array}{l}22 \\
(20.2)\end{array}$ & $17(15.6)$ \\
\hline
\end{tabular}

The barriers of the virtual training module were assessed using six statements (Table 3). Absence of eye contact during the learning was the most important barriers revealed by the students $(n=57,52.3 \%)$, followed by the lack of suitable/quiet place during the virtual training $(n=45.41 .3 \%)$, lack of access for certain technical support $(n=44,40.4 \%)$, and lack of time $(n=44,40.4 \%)$. 
Table 3

Pharmacy Students' perceived barriers of the virtual training module $(n=109)$

\begin{tabular}{|llll|}
\hline Statements & $\begin{array}{l}\text { Strongly } \\
\text { agree/Agree }\end{array}$ & Neutral & $\begin{array}{l}\text { Strongly } \\
\text { disagree/ } \\
\text { Disagree }\end{array}$ \\
\hline $\begin{array}{l}\text { The used virtual training tools (i.e. online platforms and } \\
\text { videos) created a barrier for my learning }\end{array}$ & $40(36.7)$ & $\begin{array}{l}38 \\
(34.9)\end{array}$ & $31(28.4)$ \\
$\begin{array}{l}\text { Poor internet connection } \\
\text { Non-availability of well-functioned device }\end{array}$ & $41(37.6)$ & $\begin{array}{l}43 \\
(39.4)\end{array}$ & $25(22.9)$ \\
\hline Absence of eye contact during the learning & $42(38.5)$ & $\begin{array}{l}38 \\
(34.9)\end{array}$ & $29(26.6)$ \\
\hline Lack of suitable/quiet place during the virtual training & $57(52.3)$ & $\begin{array}{l}36 \\
(33.0)\end{array}$ & $16(14.7)$ \\
\hline Lack of access to certain technical support & $45(41.3)$ & $\begin{array}{l}42 \\
(38.5)\end{array}$ & $22(20.2)$ \\
\hline Lack of enough time & $44(40.4)$ & $\begin{array}{l}39 \\
(35.8)\end{array}$ & $26(23.8)$ \\
\hline $\begin{array}{l}\text { Insufficient training using the virtual training tools (i.e. online } \\
\text { platforms and videos) }\end{array}$ & $36(33.0)$ & $\begin{array}{l}35 \\
(451.3)\end{array}$ & 28 (25.7) \\
\hline
\end{tabular}

Finally, students were asked about their perception towards suggestions that may modify the quality of the virtual training (Fig. 2). Almost half of the students agreed/strongly agreed to combine the virtual and conventional techniques for future training and to convert video records to interactive meetings with the preceptors ( $n=56,51.4 \%$ for both). Also, $45.9 \%$ of the students $(n=50)$ agreed/strongly agreed to keep the training sessions with one preceptor rather than multiple preceptors. Only $26.6 \%$ of the students $(n=$ 29) reported that no modifications are required.

\section{Discussion}

While professional community pharmacy practice training has been long incorporated into the curriculum at many pharmacy schools and health institutions $(16,17)$, the concept of virtual professional pharmacy training is still a relatively new concept for some Jordanian pharmacy schools. Moreover, due to the ongoing global COVID-19 pandemic, all virtual pharmacy training has been regarded as a logical training option for sustaining pharmacy education and skills. Additionally, there are variations across pharmacy schools, nationally and internationally, who commence such type of professional virtual training in terms of content and delivery with some tailored to the competency standards or context where such program is located (18-20). 
This descriptive cross-sectional study aimed to explore senior pharmacy students' perceptions of the value and relevance of the virtual-based pharmacy training targeting community pharmacy competencies during the COVID-19 pandemic and the influence of different variables on their perception. Additionally, this study identified the extent to which they agree with suggestions to enhance the quality of virtualbased pharmacy training from their own perspectives.

Findings from this study show that during a virtual-based pharmacy training module, preceptors positively influence their students through acknowledgment of their role as training students, integration of therapy knowledge into patient care, and assistance to achieve objectives of such training. Relatively similar, pharmacy students denied the interference of preceptors with their learning in a previous study by Darr et. al. involving a virtual training course (21). Nevertheless, the application of interesting learning activities by preceptors of virtual-based pharmacy training was regarded deficient by the students.

A study by Lucas et. al. described better student learning and confidence levels before advancing to their pharmacy placements as a result of participating in a virtual pharmacy program (22), while Ambroziak et. al. described better students' self-identification of practice required to gain pharmacy dispensing skills after engaging in a virtual pharmacy course activity (23), such benefits are particularly appreciated by pharmacy students participating in our study who expressed positive perception toward some suggested benefits of a virtual-based pharmacy training module in terms of increasing their involvement with the pharmacy profession, the achievement of proficiency in training topics, knowledge of medications prior real patient exposure, improvement of self-directed learning skills, improvement of Information Technology (IT) skills, and efficient information searching skills. Basheti et. al. emphasized on the importance of real patient simulation training toward mastering several skills among pharmacy students (24), which explains the insufficient perception of suggested benefits by our participants in this study, particularly ones related to the development of social skills, critical thinking, and lifelong learning skills of the experiential learning cycle.

The sense of agency is defined as "the sense that I am the one who is causing or generating an action" (25). The sense of agency is of utmost value when it comes to controlling an external device, as it will influence its technology effect, and thus influencing people's commitment and performance toward that task (26). Participants in this study identified a prominent barrier of the virtual-based pharmacy training being the absence of eye contact, which is of particular relation to the sense of agency (27) while the other five suggested barriers were less appreciated in terms of majority, though they might be still valid for future discussion including, in descending perception, lack of quiet place, technical support, and time.

A previous study by Abu Farha et. al. described recorded video tutorials as being effective supportive tools for pharmacy education (28), though using them solely might not be as effective, making a blended learning style more comprehensive (29). Pharmacy students in this study expressed expected higher levels of agreement with mainly two suggested solutions for a better quality of virtual-based pharmacy training module, which included combining virtual-based training with conventional ones, and inclusion of interactive live sessions with their preceptors rather than recorded ones. 
Limitations of this study include the involvement of an online Google® survey that is subject to security breaches yet protected by a password that is regarded as safe and only accessible by the research team. Moreover, an online survey instead of a face-to-face meeting poses reliability and authenticity risk to the study data, nevertheless the link to this online survey was only shared among a carefully picked student group through our educational platforms (Microsoft teams) meeting the inclusion criteria of this study. Considering the ongoing COVID-19 pandemic, the use of an online survey was the best approach to align with the physical and social distancing measures. Other alternative and better authentic methods could have been carried out (like institutional emails) but reduced engagement with students was a major concern, as they might not often log-in to their emails. Data representation of this study population might pose a limitation since only one cohort of pharmacy students was used from one institution who were involved in a unique program to that institution, as students' perceptions from other universities or schools may differ. As well, the lack of a control group for the study who did not receive the virtual training was one of the most important limitations.

\section{Conclusion}

This is the first study assessing this type of training which showed a positive perception towards virtual training among pharmacy students. Such results could spot the light on the value of hybrid education and training (virtual with actual) in the pharmacy field. However, there is a crucial need for well-designed studied modules to comply with the intended learning outcomes.

\section{Declarations}

Ethics approval: Ethics approval for the study was obtained from the Faculty of Pharmacy, Applied Science Private University (Approval number: 2020-PHA-31).

Availability of data and materials: The data will be made available by the corresponding author upon request.

Competing interests: All authors declare that they have no conflict of interest.

Funding: This study has not received any funds.

Authors' contributions: All authors were involved in all parts of the study and manuscript preparation including literature search, study design, analysis of data, manuscript preparation, and review of the manuscript.

Conflicts of Interest: All authors declare that they have no conflict of interest.

Consent to publish: Authors consent for publication of their identifiable details in relation to "Perception of Jordanian Pharmacy Students towards Community Pharmacy-Virtual Training Experience during COVID-19 Outbreak". 
Acknowledgments: The authors would like to thank all the participating pharmacy preceptors for their fruitful contribution in the success of this study.

\section{Abbreviations}

COVID-19: Coronavirus disease

IQR: Interquartile range

\section{References}

1. Snyder M. Distance Learning In Higher Education: A Programmatic Approach to Planning, Design, Instruction, Evaluation, and Accreditation, A.P. Rovai, M.K. Ponton, J.D. Baker. Teachers College Press, New York, NY (2008), ISBN13: 978-0-8077-4878-7, 224 pages, U.S. \$49.00. The Internet and Higher Education. 2008;11:220-1.

2. Rothman T, Romeo L, Brennan M, Mitchell D. Criteria for Assessing Student Satisfaction with Online Courses. International Journal for e-Learning Security. 2011;1.

3. Al-Mohaithef M, Padhi BK. Determinants of COVID-19 vaccine acceptance in Saudi Arabia: a webbased national survey. Journal of multidisciplinary healthcare. 2020;13:1657.

4. Young S. Student Views of Effective Online Teaching in Higher Education. Copyright. 2006;20:65-77.

5. Bangert A. The Seven Principles of Good Practice: A framework for evaluating on-line teaching. The Internet and Higher Education. 2004;7:217-32.

6. Maddux C, Sprague D, Ferdig R, Albion P. Editorial: Online education: Issues and research questions. Journal of Technology and Teacher Education. 2007;15:157-66.

7. Etter J-F. A self-administered questionnaire to measure cigarette withdrawal symptoms: the Cigarette Withdrawal Scale. Nicotine \& tobacco research : official journal of the Society for Research on Nicotine and Tobacco. 2005;7(1):47-57.

8. Parahoo S, Santally M, Rajabalee Y, Harvey H. Designing a predictive model of student satisfaction in online learning. Journal of Marketing for HIGHER EDUCATION. 2015:1-19.

9. Ziaee V, Ahmadinejad Z, Morravedji AR. An Evaluation on Medical Students' Satisfaction with Clinical Education and its Effective Factors. Medical education online. 2004;9(1):4365.

10. Abu Farha R, Elayeh E, Zalloum N, Mukattash T, Alefishat E, Suyagh M, et al. Evaluation of Community Pharmacy Training Experience as Perceived by Jordanian Pharmacy Students: a crosssectional study. 2021.

11. Bouw JW, Gupta V, Hincapie AL. Assessment of students' satisfaction with a student-led team-based learning course. J Educ Eval Health Prof. 2015;12:23-.

12. Serwah A. Assessment of the level of satisfaction of final year's medical students with the clinical training at taif teaching hospitals, KSA. Journal of Contemporary Medical Education. 2015; Vol 1 Issue? 
13. Boynton PM, Greenhalgh T. Selecting, designing, and developing your questionnaire. BMJ. 2004;328(7451):1312-5.

14. Tabachnick BG, Fidell LS, Ullman JB. Using multivariate statistics: Pearson Boston, MA; 2007.

15. Taber KS. The use of Cronbach's alpha when developing and reporting research instruments in science education. Research in Science Education. 2018;48(6):1273-96.

16. Al-Wazaify M, Matowe L, Albsoul-Younes A, Al-Omran OA. Pharmacy education in jordan, saudi arabia, and kuwait. American journal of pharmaceutical education. 2006;70(1).

17. AbuBlan RS, Nazer LH, Jaddoua SM, Treish IM. A Hospital-based Pharmacy Internship Program in Jordan. American journal of pharmaceutical education. 2019;83(3).

18. Douglass MA, Casale JP, Skirvin JA, DiVall MV. A virtual patient software program to improve pharmacy student learning in a comprehensive disease management course. American journal of pharmaceutical education. 2013;77(8).

19. Marriott JL. Use and evaluation of "virtual" patients for assessment of clinical pharmacy undergraduates. Pharmacy Education. 2007;7(4).

20. Hussainy SY, Styles K, Duncan G. A virtual practice environment to develop communication skills in pharmacy students. American journal of pharmaceutical education. 2012;76(10).

21. Darr AY, Erickson S, Devine T, Tran T. Design and students' perceptions of a virtually facilitated outpatient pharmacy practice laboratory course. Currents in Pharmacy Teaching and Learning. 2019;11(7):729-35.

22. Lucas C, Williams K, Bajorek B. Virtual pharmacy programs to prepare pharmacy students for community and hospital placements. American journal of pharmaceutical education. 2019;83(10).

23. Ambroziak K, Ibrahim N, Marshall VD, Kelling SE. Virtual simulation to personalize student learning in a required pharmacy course. Currents in Pharmacy Teaching and Learning. 2018;10(6):750-6.

24. Basheti IA. The effect of using simulation for training pharmacy students on correct device technique. American journal of pharmaceutical education. 2014;78(10).

25. Gallagher S. Philosophical conceptions of the self: implications for cognitive science. Trends in cognitive sciences. 2000;4(1):14-21.

26. Vlek R, van Acken J-P, Beursken E, Roijendijk L, Haselager P. BCl and a User's Judgment of Agency. Brain-Computer-Interfaces in their ethical, social and cultural contexts: Springer; 2014. p. 193-202.

27. Ulloa JL, Vastano R, George N, Brass M. The impact of eye contact on the sense of agency. Consciousness and cognition. 2019;74:102794.

28. Abu Farha RK, Rashad M, Hasen E, Mukattash TL, Al-Hashar A, Basheti IA. Evaluation of the effect of video tutorial training on improving pharmacy students' knowledge and skills about medication reconciliation. Pharmacy Practice (Granada). 2020;18(1).

29. Baumann-Birkbeck L, Florentina F, Karatas O, Sun J, Tang T, Thaung V, et al. Appraising the role of the virtual patient for therapeutics health education. Currents in Pharmacy Teaching and Learning. 2017;9(5):934-44. 


\section{Figures}

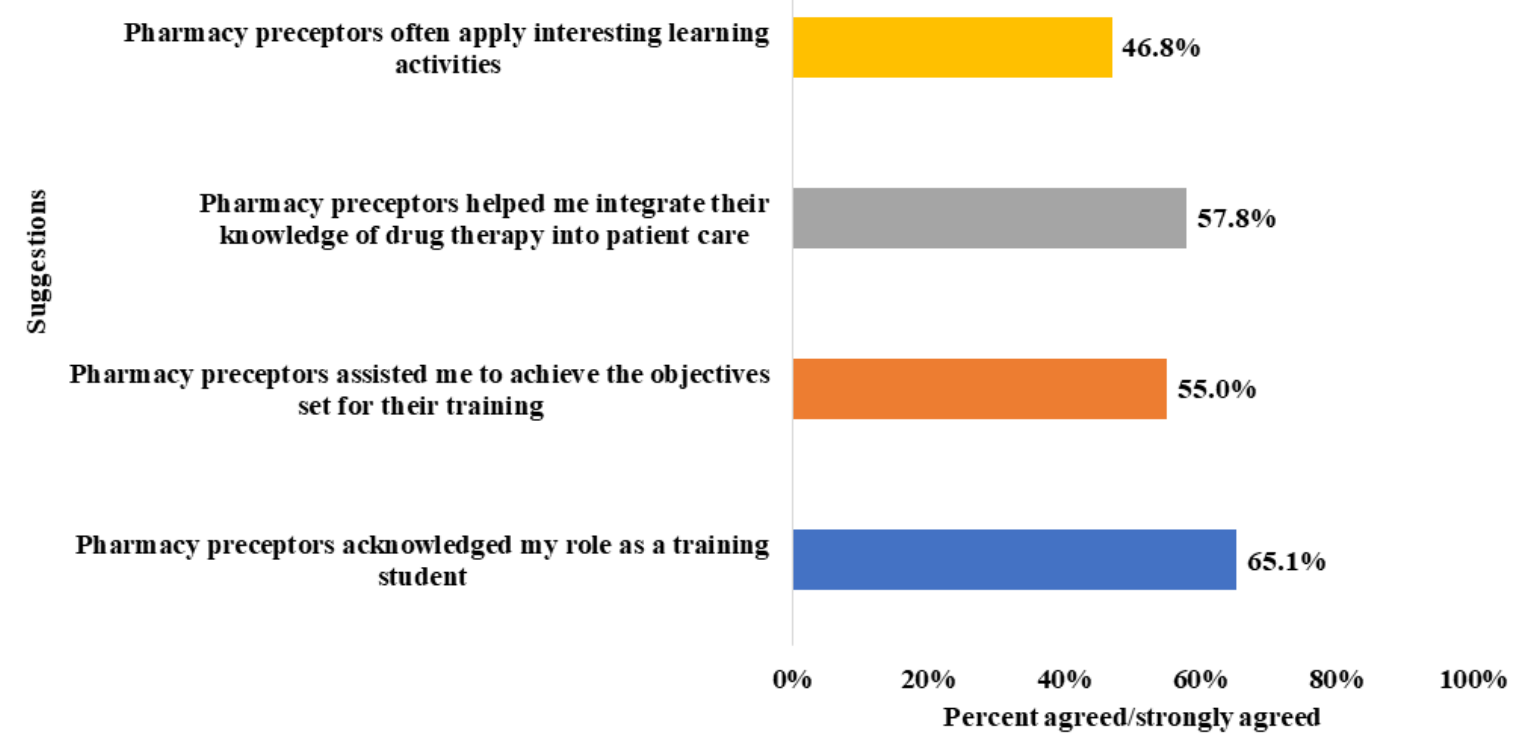

Figure 1. Pharmacy students' Perception towards training preceptors $(n=109)$

\section{Figure 1}

Students reported adequate perceptions towards preceptors participated in their virtual training course (Figure 1), where $65.1 \%$ of them $(n=71)$ believed that preceptors have acknowledged their role as training students, and $57.8 \%$ of them $(n=63)$ agreed/strongly agreed that preceptors have helped them integrating their knowledge of drug therapy into patient care. 


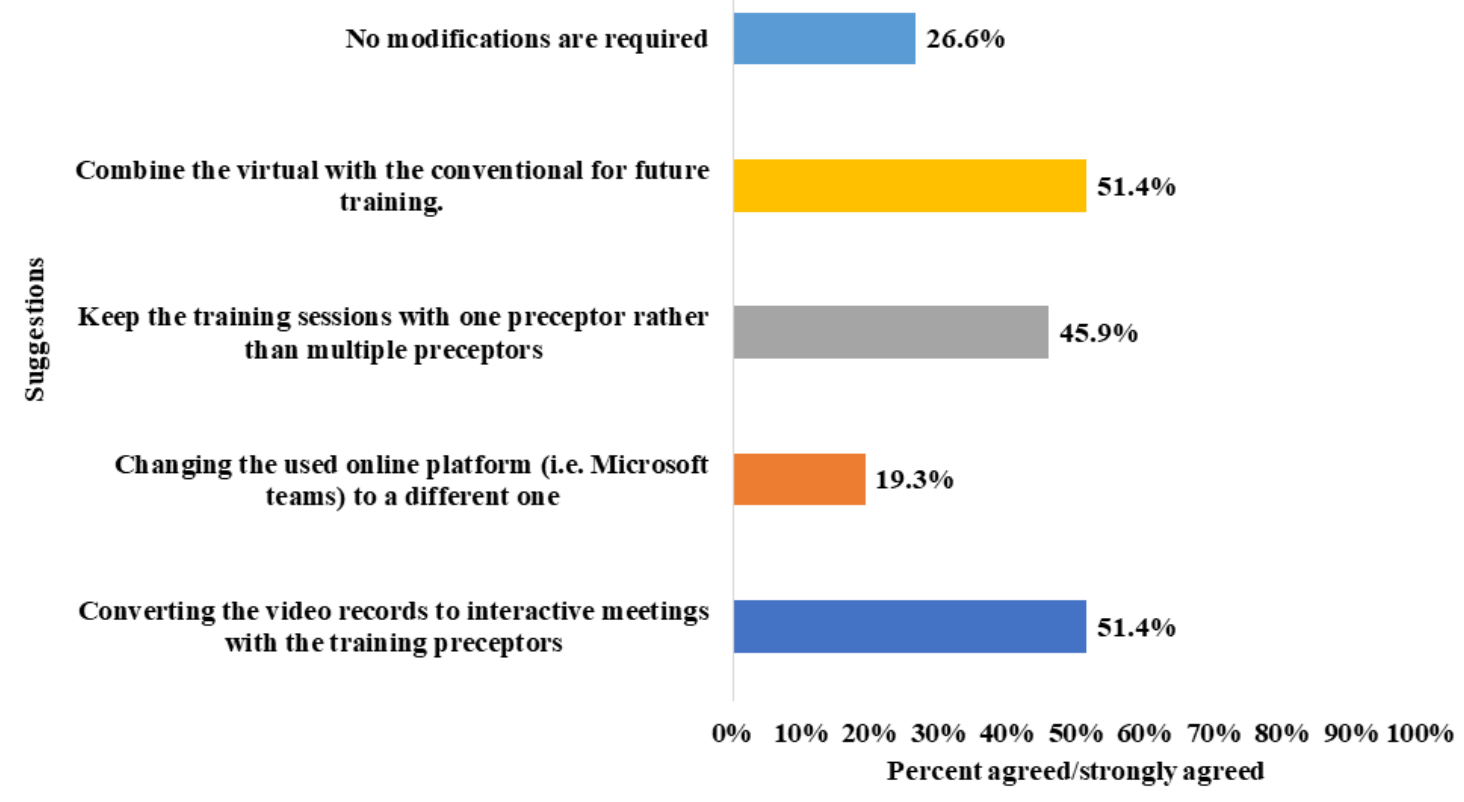

Figure 2. Suggestions to enhance the quality of virtual training from pharmacy students' perspectives $(n=109)$

\section{Figure 2}

Finally, students were asked about their perception towards suggestions that may modify the quality of the virtual training (Figure 2). Almost half of the students agreed/strongly agreed to combine the virtual and conventional techniques for future training and to convert video records to interactive meetings with the preceptors ( $n=56,51.4 \%$ for both). Also, $45.9 \%$ of the students $(n=50)$ agreed/strongly agreed to keep the training sessions with one preceptor rather than multiple preceptors. Only $26.6 \%$ of the students $(n=$ 29) reported that no modifications are required. 